Dr. Lever will be accompanied by two of his colleagues at St. Mary's, Dr. J. J. Brown and Dr. J. I. S. Robertson: all three have worked together on similar problems for some years. The team will also include a zoologist, Mr. M. Tree. Dr. Lever expects the unit to start work in the spring.

\section{Catalogue of Inventions}

THe National Research and Development Corporation has a responsibility to assist development work in industry which is technologically novel and also likely to be financially beneficial to the nation. One of its chief means of putting itself across to industry is its six monthly bulletin Inventions for Industry. Unfortunately but perhaps inevitably, this bulletin has the failing of many parish magazines in that much of its material is familiar to those who have read the previous issue. Of special interest in issue No. 29, however, is the review of development which reports on projects as different as the production of a prototype table reproducing a relief map, a semi-automatic jelly tester and a particle size micrometer and analyser. Most of these projects are well under way and in some instances dates are given when firm orders can be taken. One especially novel project is the development of the sectional or multi-packet ships system devised by Hay and Smart (Projects), Ltd., which the Ministry of Public Building and Works has decided to apply to hopper barges used in conjunction with coastal dredgers. Also of interest is "Industrial Partners Sought"- - a kind of good cause column-because it gives some insight into the corporation's future interests. This time it is inviting participation of organizations in programmes concerned with flameproofing of organic materials, effluent treatment, and the applications of plasma and high temperatures.

\section{Too Cold to Live}

Hypothermia - the condition of patients whose body temperature has fallen below $35^{\circ} \mathrm{C}$-is badly understood despite its frequency. Some scattered experience was codified by the British Medical Association in 1964, but few hard facts were then available. The report of the Committee on Accidental Hypothermia of the Royal College of Physicians (Royal College of Physicians, London, 1966) adds some badly needed statistical and clinical material to the body of knowledge about the condition.

The committee analysed the records of all patients with hypothermia admitted to ten widely scattered British hospitals from February 1 to April 30, 1965. 18,000 patients were included in the survey, and 126 of these had temperatures below $35^{\circ} \mathrm{C}$. Seventeen patients had primary hypothermia: in the other cases there were complications, mostly debilitating diseases, shock or brain damage.

Forty-two per cent of the hypothermics were over 65 years old. Many of these old people were living alone in poorly heated rooms, sometimes with inadequate clotbing. Others were severely ill from other causes. The other principal group, which made up nearly a quarter of the cases, consisted of infants under 1 year old. A number of these had malforma. tions of the brain, probably affecting the medullary centres concerned with temperature control. These infants mostly become cold in the ambulance on the way to the hospital. Normal infants with hypothermia usually came from cold houses and had inadequate mothers.

The death rate from hypothermia is high-fortyseven of the 126 hypothermic patients died. The death rate varies with the depth of hypothermia eleven of the fifteen with temperatures below $30^{\circ} \mathrm{C}$ died. Altogether seventeen died without attaining $35^{\circ} \mathrm{C}$, but the majority of the other deaths occurred 2 or 3 days after regaining normal temperature. Hypothermia is thus a serious and fairly common condition, which can easily be recognized provided it is looked for. Some cases could undoubtedly be avoided by improving the living conditions of the very old. There also seems to be a case for using low reading thermometers where hypothermia is suspected.

\section{More Neutrinos at CERN}

CERN appears to be hopeful about the next neutrino experiments now being planned at Geneva. Since the first neutrino experiments at the laboratory, several improvements in technique have been carried out so as to increase the rate at which neutrinos are produced by protons from the $28 \mathrm{GeV}$ proton synchrotron, and the theoretical rate at which neutrons are likely to be detected is expected to have increased from something like one every ten or twenty days three years ago to between 10 and 100 events a day in the series of experiments due to begin in March 1967.

Neutrinos are produced by extracting the proton beam from the accelerator, producing secondary particles by collision with the target, and counting on the decay of positive pions and kaons to yield neutrinos. The improvements which have been carried out in the past few months consist chiefly of a new focusing system, by means of which the immediate precursors of the neutrinos are first gathered by a magnetic horn and then brought into line by two magnetic correcting elements. The new arrangement is thought likely to prove roughly 1.5 times as effective as the previous one, so that the probability that a neutrino produced in the decay of a pion or kaon will pass through the heavy organic bubble chamber will be roughly three times as great as in the previous arrangement. The rebuilding of the focusing arrangement has also provided an opportunity for rearranging the 6,000 ton steel shield (lent by the Swiss Government) which is used to remove unwanted particles from the neutrino beam. Coupled with an increase in the size of the bubble chamber from 500 to 1,1801 ., these improvements are likely to increase by a factor of 40 the number of neutrino events detected for each proton produced in the accelerator. The laboratory at CERN is looking forward to the still greater efficiency there will be when the "Gargamelle" heavy liquid bubble chamber now being built at Saclay is completed in 1969.

In the first experiments, in which the heavy liquid bubble chamber will be filled with propane, it is expected that neutrinos will interact with carbon atoms five times as frequently as with free protons. Events of the two kinds will be distinguished by using a magnetic field of 27,000 Gauss. There will be a few interactions between neutrinos and free protons each day, which implies that some time will go by before there are enough events to provide significant information about inelastic collisions between neutrinos and 